\section{INNOCENT STATEMENTS}

\author{
AND THEIR
}

METAPHYSICALLY LOADED

COUNTERPARTS

\section{Thomas Hofweber}

Department of Philosophy

University of North Carolina at Chapel Hill

(C) 2007 Thomas Hofweber <www.philosophersimprint.org/oo70o1/>
$\mathrm{T}$

HERE IS AN OLD PUZZLE ABOUT ONTOLOGY, one that has been puzzling enough to cast a shadow of doubt over the legitimacy of ontology as a philosophical project. The puzzle concerns in particular ontological questions about natural numbers, properties, and propositions, but also some other things as well. It arises as follows: ontological questions about numbers, properties, or propositions are questions about whether reality contains such entities, whether they are part of the stuff that the world is made of. The ontological questions about numbers, properties, or propositions thus seem to be substantive metaphysical questions about what is part of reality. Complicated as these questions may be, they can nonetheless be stated simply in ordinary English with the words 'Are there numbers/properties/propositions?' However, it seems that such a question can be answered quite immediately in the affirmative. It seems that there are trivial arguments that have the conclusion that there are numbers/properties/ propositions. These arguments start with only completely uncontroversial premises and lead to this conclusion in a few simple and apparently uncontroversial steps. (We will look at these arguments in detail shortly.) But how that could be so is puzzling. How could it be that the substantial ontological questions have an immediate trivial answer? Maybe the project of a philosophical ontology has to be understood in different terms to resolve this puzzle, or maybe something has gone wrong somewhere else.

One of the crucial steps in these trivial arguments is the transition from an innocent statement to one of its metaphysically loaded counterparts. This step is the main focus of the present paper. I will argue that the accounts proposed in the literature that deal with these trivial arguments make a common, but mistaken, assumption about this transition, one that is a mistake not in metaphysics but in the philosophy of language. This assumption is in conflict with the best answer to some puzzles in the philosophy of language to which these trivial arguments also give rise. These puzzles in the philosophy of language can be solved only if we give up that assumption. And this leads to a new solution to the puzzle about ontology. 


\section{The metaphysical puzzle}

1.I The trivial arguments

By an innocent statement I mean a simple everyday statement that apparently has nothing to do with metaphysics. Here are two examples of innocent statements:

(1) Fido is a dog.

(2) Jupiter has four moons.

It seems surprising that from them anything of metaphysical interest should follow, much less follow almost immediately. However, just that seems to be the case. All these statements have one or more of what I'll call metaphysically loaded counterparts. These are statements that can be obtained from the former by a simple procedure and are apparently equivalent to them. I'd like to point out right away that I am not assuming that there is an asymmetry between them - for example, that the innocent statements are in some sense more basic. The procedure goes both ways. From the metaphysically loaded statements you can obtain the innocent ones in a similar manner. The above statements have at least the following metaphysically loaded counterparts:

(3) That Fido is a dog is true.

(4) Fido has the property of being a dog. ${ }^{1}$

(5) The number of moons of Jupiter is four.

It seems that they are truth-conditionally equivalent to the innocent statements simply because it seems it can't be that it's true that Fido is a dog but Fido isn't a dog. Or that Fido is a dog but it's not true that he is a dog. And it seems that it can't be that the number of moons of Jupiter is four but Jupiter doesn't have four moons. Or that Jupiter has

1. Or equivalently: Fido has the feature, or characteristic, of being a dog. four moons but their number isn't four. However, these statements don't seem to be metaphysically innocent any more. Whereas the innocent statements are only about moons and dogs, their metaphysically loaded counterparts are about truth, propositions, numbers, and properties. In addition, the metaphysically loaded counterparts immediately imply that there are propositions, properties, and numbers. The following seem to follow right away:

(6) Something is true, namely that Fido is a dog.

(7) There is a property that Fido has, namely being a dog.

(8) There is a number that is the number of moons of Jupiter, namely four.

And these immediately imply that there are propositions (i.e., whatever that-clauses stand for), properties, and numbers.

But how could we have gotten that so easily? Weren't metaphysics and ontology supposed to be difficult? How could we get results in ontology with arguments that start with completely innocent premises in just three simple steps? The above arguments seem to get ontological results out of nowhere. Our talk about properties, propositions, and numbers has what Stephen Schiffer has called the something-from-nothing feature. ${ }^{2}$ It can be introduced "from nothing" - i.e., from talk that isn't explicitly about properties, propositions, and numbers - without change of truth conditions. And through the introduction of terms that stand for properties, propositions, and numbers without change of truth conditions, we immediately get that there are properties, propositions, and numbers. All this leaves us with the question: How can we get something from nothing?

The puzzle how we can get something from nothing is a puzzle about ontology. In particular, it is a puzzle about what ontological questions are and how they are to be answered. If the ontological questions simply are questions like 'Are there numbers/properties/

2. See [Schiffer, 1994] and [Schiffer, 2003]. 
propositions?' then it seems that the above trivial arguments would answer them, if they are correct. But if they are not correct, then it won't be easy to say what is wrong with them. Surely, the premises are not in dispute, since the arguments can use as their only premise any ordinary statement. of the appropriate form. But if one of the steps is to be rejected, it will take some work to explain which one and why. After all, they seem to be valid steps of reasoning, and in fact, one might be hard pressed to find easier and more obvious arguments in philosophy. But if they are correct, then we will have to change our conception of some of the classic problems in ontology, how they are to be solved, or how to express ontological questions. The crucial step in understanding this is to understand what is going on in the transition between the innocent statements and their metaphysically loaded counterparts.

In the following we will look at some accounts of how to deal with the puzzle how we can get something from nothing. Then we will notice a common assumption in all of these accounts, one that comes from the philosophy of language and that we have to reject. Finally, we will return to metaphysics and outline a new solution to the puzzle of how we can get something from nothing.

\subsection{The standard solutions}

There are a number of solutions in the literature to the puzzle how we can get something from nothing, and I will call them the standard solutions. We won't discuss them here in any detail, since we will focus on an assumption they all share.

The modern debate about the relation between the innocent statements and their metaphysically loaded counterparts goes back to Frege - in particular, his Grundlagen [Frege, 1884]. There Frege was concerned with, among other things, the question whether numbers are objects. He observed that in uses like

(2) Jupiter has four moons.

number words like 'four' apparently are not used in the way that ex- pressions that stand for objects are used. Their use seems more similar to that of adjectives, like 'green':

(9) Jupiter has green moons.

However, in other uses 'four' does seem to be used like expressions that stand for objects, for example:

(5) The number of moons of Jupiter is four

This seems to be similar to

(10) The composer of Tannhäuser is Wagner.

It seems that both (5) and (10) are identity claims in which it is said that what two singular terms stand for is identical. And this suggests that number words stand for objects.

Frege wasn't too clear about how we should understand the uses of number words in natural language as in (2), in which they apparently aren't singular terms. Or at least it isn't clear to me what Frege thought. Are we to believe that English contains two words spelled 'four' that belong to two different syntactic and semantic categories? If not, how do the two uses relate to each other? One might be inclined to understand Frege as claiming that we really always refer to numbers when we use number words, even when we use them as adjectives. Such uses might be a confusing way of speaking that occurs in an imperfect natural language. ${ }^{3}$ Questions about natural language were certainly not Frege's main concern; that was mathematics. But still, the question about natural language remains, and it is the relevant one for our worry here. And some of the things Frege says in [Frege, 1884] certainly suggest a position about natural language as well, whether or not this was his main concern.

This part of the Fregean story is one of its weak points, even in its contemporary, neo-Fregean versions. In contemporary natural-language semantics the uses of 'four' as in (2) are pretty well understood,

3. See [Frege, 1884$] \S 57$, where Frege seems to suggest this. 
and 'four' is usually considered to be a determiner, an expression of the same kind as 'some', 'many', and 'all'. Such expressions are not disguised referring terms. We will see more about this below. ${ }^{4}$

Frege did accept that (2) and (5) are truth-conditionally equivalent. Thus, he held that (2) is true if and only if (5) is true. Let's call a statement affirming the truth-conditional equivalence between an innocent statement and one of its metaphysically loaded counterparts a Frege biconditional. Frege did accept Frege biconditionals, at least for the case of numbers. Anyone who accepts the truth of Frege biconditionals has to accept the first step in the trivial arguments above. And it is hard to see how one could accept the first step while resisting the second. Thus anyone who accepts the Frege biconditionals has to face the puzzles we started out with - in particular, how we could have gotten substantial ontological results from metaphysically innocent premises. One way of understanding Frege is that these inferences are not puzzling because we never started out with metaphysically innocent statements. If 'four' is always a referring expression, then it should be no wonder that (2) immediately implies that there are numbers. The apparently innocent statement wasn't that innocent after all.

Frege also used a very suggestive metaphor for the relationship between pairs like our innocent statements and their loaded counterparts. He said that we can carve up content in different ways, and this can give us new concepts. ${ }^{5}$ Frege's examples for which he discusses this are slightly different than ours here, but still, the metaphor has its force here, too. Suggestive as it is, it is not clear how to understand it more precisely. If an innocent statement and its loaded counterparts have the same content carved up in different ways, then there is no puzzle about why they are equivalent, but it remains mysterious how that could be possible. How could it be that the same content one time is about a certain object but the other time is not? How should we understand "carving" of contents? To use this metaphor is simply a

4. Number words in natural language are also discussed in detail in [Hofweber, 2005a].

5. See [Frege, 1884] $\$ 64$. way to state the puzzle we are after here: how can it be that there are apparently equivalent ways of saying the same thing that are nonetheless about different entities? A solution to this problem will give us a way to spell out the carving metaphor. We will spell out below how content carving is to be understood according to the solution to the puzzle proposed in this paper.

A second solution to the metaphysical puzzle is inspired by Frege but tries to draw the more or less opposite conclusion. There are a number of subtly different versions of this second solution, and they are discussed in a slightly different context in the debate about neoFregean philosophy of mathematics. Since we will not get into the details here, I will just state a simple version of such a solution. ${ }^{6}$ The main idea of this second solution to the puzzle how we can get something from nothing is that we don't get something from nothing, although the loaded counterparts make it seem that we do. The loaded counterparts don't imply that there are numbers, properties, or propositions because they can be paraphrased away as an innocent statement. And because there is such a paraphrase, the loaded counterparts are themselves innocent. It is because we can avoid commitment through paraphrase that we don't get something from nothing.

A third solution to the puzzle does take it somewhat literally that we get something from nothing. Stephen Schiffer has argued, at least in the case of properties and propositions, that we do get something from nothing, and that reflects on the entities we get. Properties and propositions are pleonastic entities, ones whose existence is guaranteed simply by talking about them with the loaded counterparts. ${ }^{8}$ In

6. For more on this general line in the context of a neo-Fregean philosophy of mathematics, and different versions of it, see [Rosen, 1993] and [Hale and Wright, 2001].

7. This is, of course, a very controversial strategy. Avoiding ontological commitment via paraphrase has been criticized by Alston in [Alston, 1958], but we will not criticize the proposal now. Criticism will follow shortly. There are also better but more complicated versions of this general strategy available but they are more involved, and we don't have to discuss them here.

8. See his recent book [Schiffer, 2003]. 
fact, he has called them "language created entities" [Schiffer, 1996], ones that are created by a certain way of speaking. ${ }^{9}$ According to this solution, there are second-class entities whose existence is guaranteed simply by talking a certain way. We do get something from nothing, but what we get are second-class entities.

All of the solutions so far accept the Frege biconditionals as true. But there are also those, finally, who deny them, but who have an explanation why they seem true to us. Most prominently, there are fictionalists who hold that the loaded counterparts are not literally true and are not strictly equivalent to the innocent statements. Rather, they are only true within the fiction that there are numbers, properties, and propositions. And within that fiction they are equivalent to the innocent statements, although outside of the fiction they are not. Thus, they are equivalent only given that there are numbers, properties and propositions. This option has been endorsed by Hartry Field, in [Field, 1989a], and Stephen Yablo, in [Yablo, 2006]. ${ }^{10}$

We will not look at these proposals in more detail here since we will momentarily raise an issue that all standard approaches seem to neglect, and which will motivate an alternative approach. We can however summarize the above four approaches in four answers that can be given to the question "How can we get something from nothing with these trivial inferences?":

A1 We don't get something from nothing, because we never started with nothing. We started with something, even though it was hidden.

9. Even though Schiffer says this, it is actually not literally true on his view, since propositions exist necessarily and at all times. The creation line is close in spirit to his earlier, [Schiffer, 1996], but not very congenial to his later, [Schiffer, 2003], view.

10. This is not the place to criticize fictionalism. But to really hold this fictionalist line one must believe that fiction goes very deep in our ordinary discourse. After all, the inference from an innocent statement to one of its metaphysically loaded counterparts goes naturally, for anyone, not just those in the metaphysics classroom. It won't be easy to defend the claim that fiction goes that deep.
A2 We don't get something from nothing, because paraphrases avoid ontological commitment.

A3 We do get something from nothing. This, however, reflects the nature of the entities we get. They are second-class entities that are created by a certain practice of speaking.

A4 We don't get something from nothing, because Frege biconditionals are not true and the innocent statements don't imply their metaphysically loaded counterparts.

\section{Some syntactic and semantic puzzles}

The above solutions to the metaphysical puzzle treat it as such, a puzzle in metaphysics. Although each one has its own problems when seen as a metaphysical solution to a metaphysical puzzle, we will not focus on these problems here. We will rather concentrate on a number of puzzles in the philosophy of language that are also closely associated with the innocent statements, their loaded counterparts, and their apparently obvious equivalence. In this section we will first look at a common semantic assumption in all of the above solutions. Then we will raise some prima facie problems for this assumption. After that we will present our main argument that this assumption is mistaken, and finally, we will offer a different solution to the metaphysical puzzle as well.

All of the above solutions agree that in literal uses the metaphysically loaded counterparts contain new and different semantically singular terms, compared to the innocent statements. By a semantically singular term I mean a singular term that has as its semantic function to pick out, refer to, or denote some entity. All of the above accounts hold that in literal uses of the loaded counterparts the phrases the number of moons', 'the property of being a dog', and 'that Fido is a $\operatorname{dog}^{\prime}$ have the semantic function of denoting some entity. Now, they disagree about whether standard uses of the loaded counterparts are literal uses, whether the entity has to exist, and what the metaphysical nature of these entities is. But the semantic function of these phrases 
is not in dispute among the standard solutions. And there is good reason to hold that these phrases are semantically singular terms. After all, 'the number of moons' looks like a definite description, just like 'the composer of Tannhäuser'. And all of them interact with quantifiers in just the way that one would expect of a referring expression. But this assumption has its problems. Some of them might be overcome. I will first mention a few of these, but I won't claim here that they are devastating and require a rejection of this view. However, I will then also present some problems which do require the rejection of this assumption. This will be the main task of the paper.

Before we look at the prima facie arguments against this assumption we should clarify what is at issue here. The issue is not whether these phrases can be used as referring or denoting expressions, or even whether they sometimes are used that way. This would be hard to deny. After all, speakers can use an expression that semantically denotes one thing with the intention to denote another, and they can use an expression that semantically denotes nothing with the intention to denote a particular thing. I do not want to deny this. Furthermore, since 'number' is a common noun it can be used to form a definite description 'the number', which is perfectly meaningful and a semantically singular term; the same goes for 'the number of moons'. What is at issue is rather what is going on in the common usage of the loaded counterparts when we infer them from the corresponding innocent statements. It might well be that 'the number of moons' can be and sometimes is used as a definite description, but the question is how is it used in a common usage of the loaded counterparts when making the trivial inferences. Compare this to the question of what the semantic function is of 'the tiger' in a common usage of

(11) The tiger is fierce.

Since 'tiger' is a common noun it can be used to form the definite description 'the tiger', which aims to denote the one and only tiger. But this is not how it is used in a common utterance of (11). An ordinary utterance of (11) more likely is a generic use of it, which is more like
(12) Generally, tigers are fierce.

So what is the semantic function of the relevant phrases in common uses of the metaphysically loaded counterparts when we make the trivial inferences?

The standard solutions agree that the loaded counterparts contain new singular terms, and that these singular terms in literal uses have the function to stand for, or denote, a particular entity. But even though the notion of a singular term is appealing, it is not clear what expressions fall under it, and in particular it is not clear that these expressions have the same semantic function. ${ }^{11}$ In fact, it seems that even the paradigmatic cases of singular terms are in important ways semantically different, even though they can be said to be about a single thing. Referring expressions and definite descriptions are paradigmatically singular terms, but they are really of two different semantic kinds. Both can be said to be "about a single thing", but this is true only in two different senses of this phrase. Referring expressions are about a single thing in the sense that they have it as their semantic function to pick out and contribute to content whatever they refer to. Descriptions, on the other hand, are commonly taken to be quantifiers that have a certain uniqueness built into them. They are about a single thing in the sense that there has to be a single thing that has the properties specified by the description in order for certain sentences in which the description occurs to be true. ${ }^{12}$ In this sense the descrip-

11. The notion of a singular term has gotten quite a bit of attention in the philosophical literature, since it plays a central role in neo-Fregean programs in the philosophy of mathematics. In this tradition there are attempts to give a more precise characterization of this notion, in particular [Dummett, 1973] [Hale, 1987], and essays 1 and 2 in [Hale and Wright, 2001], amongst others. Neo-Fregeans usually attempt to characterize this notion purely syntactically, and they argue that all singular terms have a uniform semantic function, namely to denote objects. Our discussion here is very relevant for this literature, but since we are not primarily concerned with neo-Fregean approaches to mathematics we won't discuss it here in detail.

12. The qualification "certain sentences" is merely to enable us to rule out negative sentences, or conditionals, etc., where the existence of a unique thing might not be required for the truth of a sentence containing a description. 
tion can be said to be about that thing. But this is really a quite different sense of being about something.

Furthermore, there are a number of expressions that might also be seen as being singular terms but that intuitively do not have the function of picking out some entity. Consider, for example,

(13) What Mary likes to do on Sundays is fishing.

(14) Softly is how Mary spoke.

(15) How Mary made the chocolate cake is with a lot of care.

These can be seen as singular terms because they seem to satisfy conditions that are often believed to be essential for singular terms, like occurring in true "identity" claims, as in:

(16) How Mary makes a chocolate cake is identical to how my grandfather used to make it.

Does this show that 'how Mary makes a chocolate cake' stands for an entity? Does this really have any metaphysical or ontological consequences?

Maybe relying on the notion of a singular term is a mistake and a red herring. It seems sufficient to instead rely on the better understood notions of a definite description and of a name, the paradigm of a referring expression. These seem to be all that the standard accounts need in order to understand the numbers case. The standard accounts hold that semantically

(5) The number of moons of Jupiter is four.

is just like

(10) The composer of Tannhäuser is Wagner.

Since 'the composer of Tannhäuser' is pretty clearly a description, and

In addition, I am, of course, assuming that the description theory of names is incorrect. That singular terms form a semantic kind is usually not taken to depend on the description theory of names.
'Wagner' is pretty clearly a referring expression, the standard accounts can thus be taken to hold that 'the number of moons of Jupiter' is a description, and 'four' is a referring expression, as they are used in (5) However, there are good reasons to doubt that this is so. We should look at them, one example at a time.

2.1 The number of moons

It is not at all clear whether 'the number of moons of Jupiter' is a description in common uses. In fact, it is in important respects quite different from paradigmatic descriptions like 'the composer of Tannhäuser'. A description 'the $\mathrm{F}^{\prime}$ has a close relation to another quantifier, namely 'an $\mathrm{F}^{\prime}$. With 'an $\mathrm{F}^{\prime}$ we claim that there is at least one $\mathrm{F}$, with 'the $\mathrm{F}^{\prime}$ we also claim that there is at most one. In particular, 'the $F$ is $G^{\prime}$ implies 'an $F$ is $G^{\prime}$. Thus

(10) The composer of Tannhäuser is Wagner.

implies

(17) A composer of Tannhäuser is Wagner.

and (10) further claims that Tannhäuser had only one composer. This relationship holds generally between definite descriptions 'the $\mathrm{F}^{\prime}$ and particular quantifiers 'an $\mathrm{F}^{\prime}$. However, the relation between 'the number of $\mathrm{F}^{\prime}$ and 'a number of $\mathrm{F}^{\prime}$ is interestingly different. Most strikingly, we get a difference in subject-verb agreement with them. So,

(5) The number of moons of Jupiter is four.

is perfectly fine, but

(18) A number of moons of Jupiter is four.

is quite awkward and seems to involve an agreement violation between subject and verb. However, with a plural verb as in

(19) A number of moons of Jupiter are covered with ice.

it is perfectly fine; whereas 
(20) The number of moons of Jupiter are covered with ice.

is quite clearly an agreement violation. So, 'the number of moons' requires the singular, whereas 'a number of moons' seems to require the plural. We get no similar phenomenon with standard cases of descriptions. There the agreement is the same with 'the $\mathrm{F}^{\prime}$ and 'an $\mathrm{F}^{\prime}{ }^{13}$

It seems that 'a number of moons of Jupiter' means more or less the same as 'many moons of Jupiter'. 'The number of moons of Jupiter' doesn't mean that. 'The number of moons of Jupiter' is more or less the same as 'the number of moons Jupiter has', which is closely related to, but not quite the same as, 'how many moons Jupiter has'. Just compare $(5)$ to

(21) How many moons Jupiter has is four.

Now, it should not be concluded from all this that 'a number of moons' is never used such that 'a number' is simply a quantifier, as in

(22) A man entered.

Simply because 'number' is a noun, and 'a' a determiner, we can form the quantifier 'a number'. And again, similarly for 'the number', which is well formed as a description. The question is, though, what its common uses are, and in particular for the latter, what its use is in the loaded counterparts when we make the trivial inference from an innocent statement to the loaded counterpart. The above examples show that 'a number' is often not used as a quantifier. As a quantifier it requires singular agreement with the verb, but in the above examples the plural seems to be mandatory. The question for us is whether the same might not be true for 'the number' as well, and if so, what its common

13. This connection between 'a number of Fs' and 'the number of Fs' has unfortunately been neglected in the philosophy literature. It surfaces in a passage by Hardie discussing Aristotle, who seems to have claimed that one is not a number. Hardie comments: "A man might give one as the number of his sisters, the answer to 'how many?' but also, in answer to the question whether he had a number of sisters, might say 'no-only one'" ([Hardie, 1968] 54). Thanks to Steve Darwall for this reference. uses are where it is not a description. Perhaps the Fregean analysis of these examples misses some important point. Perhaps (5) isn't really closely related to (10). But if not, what is going on in this example? And how does it relate to (10)?

\section{2 is four}

Beside the question whether 'the number of moons' in a standard use of

(5) The number of moons of Jupiter is four.

is a definite description, there is also a question about the semantic function of 'four' in this example. In fact, it gives rise to a puzzle all by itself, and this puzzle is not a metaphysical puzzle, but a semantic and syntactic one. Frege observed that number words in natural language occur in two quite different syntactic positions. On the one hand they appear to be singular terms, as in (5); on the other hand they appear to be adjectives, or determiners, as in (2). The paradigmatic cases of words that occur in each of these syntactic positions have quite different semantic functions. But how can it be that one and the same word is syntactically both a singular term and a determiner? Other determiners, like 'many', 'some', or 'the', never occur as singular terms. And other singular terms never occur as adjectives or determiners. To mention just one example, the apparent singular term 'the number of moons of Jupiter' could not be used as a determiner or adjective without resulting in immediate ungrammaticality. If we would replace 'four' in (2) with it we would get nonsense:

(23) *Jupiter has the number of moons of Jupiter moons.

This nonsense results even though in (5) 'four' and 'the number of moons of Jupiter' are both supposed to be singular terms standing for the same object. How 'four' can occur in these different syntactic positions is in need of an explanation. ${ }^{14}$

14. This puzzle about number words in natural language is discussed in detail in [Hofweber, 2005a]. 


\subsection{Substitution failure}

The problems in the last two sections are specific to the case of numbers. The cases of properties and propositions also raise problems for the standard solutions. The assumption shared among these solutions, that the loaded counterparts in the cases of properties and propositions involve more semantically singular terms, has several well known problems, only one of which I want to repeat here. It is the so-called substitution problem. If 'that Fido is a dog' and 'the property of being a dog' are semantically singular terms, then they should be substitutable for other terms that stand for the same entity. Since they do not occur in any special, indirect contexts, they should be replaceable by co-referential terms. But this does not seem to be the case. If 'that Fido is a dog' denotes a proposition, then it should denote the same proposition as 'the proposition that Fido is a dog'. But the following two differ in truth conditions:

(24) Fred fears that Fido is a dog.

(25) Fred fears the proposition that Fido is a dog.

The first is a fear about Fido; the second is a case of proposition phobia, fear of propositions themselves. Similarly for property nominalizations like 'being a philosopher' and 'the property of being a philosopher':

(26) Being a philosopher is fun.

(27) The property of being a philosopher is fun.

These are well known examples, and I don't want to claim that they refute a view that takes the relevant phrases to denote entities. But they do raise a prima facie problem for this view, one that in my opinion has never been solved..$^{15}$ If these phrases do not denote entities,

15. There are some attempts to solve them, such as [King, 2002] or [Schiffer, 2003], but it seems to me that they fail. See [Hofweber, 2007a] and [Hofweber, forthcoming]. For more on this problem, see [Moltmann, 2003]. however, then there is no substitution problem, since we should not expect that one can be replaced by the other.

These problems so far arise for particular cases of the innocent statements and their loaded counterparts. There are also a number of them that apply to all the cases. We will look at two of them next.

\subsection{The obviousness of the equivalence}

One puzzling fact about the innocent statements and their metaphysically loaded counterparts is how obviously they are equivalent. To be sure, some people think they are not equivalent, but this is usually motivated by some philosophical considerations - for example, the consideration that they seem to be about different things and thus can't be equivalent. But if we judge them as regular English sentences and ignore metaphysical considerations, it is very hard to deny that they are equivalent. Furthermore, their equivalence is obvious to anyone, in particular those not familiar with the related metaphysical debate. The more one makes oneself aware of possible metaphysical consequences of their equivalence, the less equivalent they can seem, but the initial obviousness of their equivalence asks for an explanation. How can they be obviously equivalent given that they seem to be about different things?

One common explanation is metaphysical: it is the nature of these things that explains why the equivalence is obvious. But this strategy is problematic, since the equivalence is obvious to everyone who understands the sentences. It will take some further work to say how the equivalence can be explained by the nature of the entities in question, which isn't obvious to everyone who understands the sentences. But there might be another, non-metaphysical way to give an explanation of the obviousness of the equivalence, one that ties it to linguistic competence, not metaphysical facts about entities. In any case, some explanation has to be given here.

2.5 The puzzle of extravagance

The key to solving the above puzzles seems to me to solve another 
puzzle, which I'll call the puzzle of extravagance. It becomes vivid if we grant that Frege biconditionals are true.

It should be beyond dispute that one of the core functions of language is to communicate information. There are other things we do with language, like joking and flirting, but these uses of language seem to be derivative on the main function that it has, namely to get information from the speaker to the hearer, or to request information from the hearer. With this in mind, we can ask ourselves, why should it be that our language (like many, perhaps all, others) has systematically two ways to say the same thing? If I want to get the information across how many moons Jupiter has, why do I have two ways to do it, by either saying that Jupiter has four moons, or that their number is four? Why would our language have these extra resources?

We can look at the same puzzle from a more Gricean and pragmatic point of view. All the metaphysically loaded counterparts of the innocent statements involve more words and more elaborate sentence structure. They are, in a word, more complicated. But according to Grice's maxims I should be as cooperative as possible, and communicate the information I have in an as simple, relevant, and elegant way as I can. If I don't do this, and if I use more complicated ways to communicate than necessary, then I will often try to do something else beside communicating the information I have. In particular, the hearer's recognition that I violate one of the maxims will draw his attention to the fact that I am doing more than just trying to communicate what the sentence uttered literally means. If that is so, I might be trying to do something over and above just communicating certain information when using the loaded statements instead of their innocent counterparts. But what?

It might be that the loaded counterparts are merely a byproduct. For example, the conjunction of two sentences is always a sentence, even if the two sentences are the same. Therefore

(28) Water is wet and water is wet and water is wet and water is wet. is a well-formed sentence that is truth conditionally equivalent to

(29) Water is wet.

A general fact about our language accounts for this case of extravagance. We have a need for having conjunction in our language. And it guarantees that sentences like (28) are well formed and meaningful sentences. Thus this case of extravagance can be explained. Such sentences are simply a by-product of something else, and that something else is what we really have a need for. Are the loaded counterparts merely a by-product of something else for which we have a need in communication? Or do they themselves play a role in communication? And if so, what is it?

In the literature on philosophy of mathematics or metaphysics, where Frege biconditionals are discussed, the authors usually take sentences like (2) and (5) and reflect on their truth conditional equivalence and difference in singular terms. However, they don't discuss whether these have a different use in actual communication, and if so, what this difference is. This is a bit surprising, because it seems to be quite obvious that their use in communication is quite different, despite their apparent truth conditional equivalence. How do they differ? And do the loaded counterparts have a use in ordinary, everyday communication? We should look at these puzzles in the philosophy of language first, before we return to the metaphysical puzzle about getting something from nothing.

\section{Steps towards solving the syntactic and semantic puzzles}

An account of the relationship between the innocent statements and their metaphysically loaded counterparts should solve the puzzles we mentioned above, both the syntactic and semantic ones, as well as the metaphysical puzzle about how we can get something from nothing. In the following I will propose a solution to the syntactic and semantic puzzles first. Then I will argue that this solution also gives us a solution to the metaphysical puzzle.

To be more precise, an account of the relationship between the in- 
nocent statements and their metaphysically loaded counterparts has to include the following:

1. An account of our intuitive judgments of their truth conditional equivalence.

2. An account of whether the meaningfulness of one of the counterparts is an byproduct, or whether each of the counterparts has a function in communication. This should solve the puzzle of extravagance.

3. An account of the case-specific syntactic and semantic features - for example, an account of how 'four' can occur both as a determiner in the innocent statement and as a singular term in the loaded counterpart.

4. An account of how we can get something from nothing, that is, a solution to the metaphysical puzzle.

As we will see, a solution that performs the first three of these tasks will perform the fourth as well.

3.1 The function of the cleft construction

There are a number of fairly well known cases in natural language that are analogous to the relationship between the innocent statements and their loaded counterparts. They don't play much of a role in philosophy, but they give rise to some similar puzzles, in particular the puzzle of extravagance, and it is instructive to see how these puzzles are solved in their case. In fact, I will argue that they are rather close to our main concern. One good example of this is the so-called cleft construction: 'it is $\mathrm{X}$ that $\mathrm{Y}^{\prime}$. With it one can say what one says with an ordinary sentence like

\section{(30) Johan likes soccer.}

also with two different, but truth conditionally equivalent sentences, namely
(31) It is Johan who likes soccer.

(32) It is soccer that Johan likes.

Here, too, we have (apparently) truth conditional equivalence, but we use more words and a more complex sentence in the latter cases. So what is the difference? When would we use one but not the other? Is the meaningfulness of these sentence an byproduct, or do they play distinct roles in communication? If they play distinct roles, what is the function of the cleft construction?

The answer is quite straightforward. Even though we communicate the same information with (30), (31), and (32), we do so in a different way. In an ordinary utterance of (30), the information that Johan likes soccer is communicated neutrally. No particular aspect of the information is given a special status. In an ordinary utterance of (31) or (32), this is not so. Some aspect of what is communicated is given a special status: it is stressed. The common term for this phenomenon is focus. The focus of an utterance of a sentence is the aspect of what is said that is given a special stress or importance. The clefted sentences do just that. The above ones focus either on Johan or on soccer, respectively. They contrast what was said with other alternatives: that it was Johan and not someone else that likes soccer, and that it is soccer and not something else that Johan likes, respectively.

Clefted sentences are by no means the only way in which one can achieve a special stress. An utterance of (30) can be used to communicate the information in a non-neutral way, too. A speaker could phonetically stress one aspect or another, and this way of doing it is certainly the most common. A speaker could utter

(33) Johan likes SOCCER. ${ }^{16}$

16. The capitals here represent phonetic stress of the right kind. There are many different ways to phonetically stress a part of a sentence, and there are ways to annotate them in written text, but since the subtleties of this won't play a central role in the rest of this paper, we trust that the reader will make the proper emphasis when reading these capitals. 
(34) JOHAN likes soccer.

An utterance of (33) or (34) would not present the information neutrally. It would rather stress the fact that it is Johan who likes soccer, and not someone else, in the case of $(34)$; or that it is soccer that he likes, and not something else, in the case of (33). ${ }^{17}$ Thus (33) is a lot like (32), and (34) is a lot like (31). In each case, both can be used to communicate the same information, and in addition, both have the same focus. So it seems that in English we have at least two ways to achieve focus. We can raise our voice, or we can use a clefted sentence, where the focused item is put in a distinguished position. In written English, however, we only have the cleft construction and not the varying intonation (unless, of course, we introduce representations for phonetic stress in written English, like capital letters).

In communication we take recourse to the cleft construction for that purpose, to achieve a certain focus effect. And we do have a need in communication to do so (I will elaborate on this in a minute). We can thus say that the function of the cleft construction is to focus on the clefted item. The clefted item is the one that was extracted and given a distinguished position, for example, 'Johan' in (31).

The cleft construction is not the only construction we have for doing this. There are a number of constructions that extract a certain item in a sentence and put it in a distinguished position. The truth conditions of the sentence are unaffected by this, but a certain focus affect is achieved. Consider, for example, these pairs:

(35) John ate a sandwich.

(36) A sandwich is what John ate.

17. This kind of focus is called contrastive focus. See, for example, [Rooth, 1985] [Rochemont and Culicover, 1990], [Herburger, 200o], or [Büring, 1997] for much more on focus and its relation to syntax, intonation, and semantics.
(37) Mary spoke softly.

(38) Softly is how Mary spoke.

Thus we can say that there are at least two ways in which a focus effect can be brought about. One is intonational focus. There the particular intonation of a sentence uttered results in a focus effect. The other one is structural focus. Here the syntactic structure of the sentence brings with it the focus effect. The focus that results can be the same, but there are two different ways to get it.

3.2 Focus and communication

In communication we get information from one person to another, either through making an utterance with the right truth conditions or by requesting certain information from one of the participants in the communication. But for this to work effectively not any sentence with the right truth conditions will do. A number of aspects have to be considered that will be relevant in choosing among different sentences to utter. For example:

- What is the shared background knowledge of the participants in the communication?

- What of the information communicated is new, and what part of it is shared background, which is old?

- Is there any misinformation held by one of the participants in the communication?

- What is important and what isn't for the present purpose?

To communicate effectively it is important to make clear what is new, what is important, and what is supposed to be a correction of an earlier misunderstanding. We do this by communicating information in a certain way, and this, among other things, is what focus contributes to. 
Focus is not merely an added pragmatic feature; it can also affect the truth conditions of what is said. Consider the following examples: ${ }^{18}$

(39) John only INTRODUCED Jim to Jack.

(40) John only introduced JIM to Jack.

(41) John only introduced Jim to JACK.

(39) is false if John also took Jim and Jack fishing, but (40) and (41) can remain true under these circumstances. And (40) is false if John also introduced Jane to Jack, but (39) can remain true under these circumstances. Similarly, if John introduced Jim to Jill then (41) will be false, but (39) and (40) can be true.

One prominent proposal to deal with the semantics of focus and the effect it can have on the truth conditions of an utterance is the so-called alternative semantics. ${ }^{19}$ Simply put, we can think of focus as invoking alternatives to what was said. For example, when I focus on Johan in (34), I am invoking alternatives which can be collected in an 'alternative set', like \{Peter likes soccer, Sue likes soccer, etc.\}. When I add 'only' to this and say

(42) Only JOHAN likes soccer.

then this is true if there is no true member in the alternative set, other than possibly (34) itself. Thus, to give a compositional semantics accommodating focus we could assign besides the usual semantic values also extra and additional semantic values: alternative sets. Focus-sensitive expressions like 'only' can then contribute to the truth conditions that a certain relationship holds between the standard semantic

18. These are standard examples for the extensive literature on the semantics of focus. See, for example, [Rooth, 1985] for a well-known proposal on how to deal with such examples, which will also be outlined shortly.

19. See [Rooth, 1985]. One alternative to it is the account that uses structured meanings instead of alternative sets. These differences do not matter for our discussion here, and the two approaches are variants of each other for simple cases like the ones we are considering in this paper. For more on this, see [von Stechow, 1991] and [Krifka, 2004]. value and the alternative set. In our case involving 'only', above, an utterance of (39), (40), or (41) is true just in case the proposition that John introduced Jim to Jack is true and in addition this is the only true proposition in the contextually restricted set of alternatives. What the set of alternatives is will differ depending on which item is focused, and thus the truth values of (39), (40), or (41) can differ.

3.3 Questions, answers, and focus

Focus also has a close connection to questions and answers, one that we will rely upon in an argument below. This connection is tied to the relationship that focus has to differentiating new information from old background information. Take a simple question like

(43) Who likes soccer?

This question has a number of possible appropriate answers, basically sentences of the form

(44) X likes soccer.

Some answers with the same truth conditions as ' $\mathrm{X}$ likes soccer', however, are not appropriate, in particular

(45) It is soccer that $\mathrm{X}$ likes.

However,

(46) It is $X$ who likes soccer.

is perfectly appropriate and correct. The inappropriateness of (45) is not one of ungrammaticality, since clearly the sentence is grammatical; it is an inappropriateness in discourse. It is a failure of what is called question answer congruence. The failure is basically that the focus in the answer is on the wrong thing. What is focused in (45) is what was part of the background information, namely that soccer's being liked is under discussion. For an answer to be congruent to a question, it has to have the proper focus: it has to focus on the new information, the information that was requested. The focus alternatives in the an- 
swer have to be the possible answers to the question. This is exactly the case with question (43) and answer (46).

And this makes perfect sense. When one requests information with a question some part of the answer will be shared background information, say that someone likes soccer, or that soccer is under discussion. But other parts are not shared, and they are the ones that the person asking the question wants to get. When one gives an answer with a focus in it, one presents the focused item as new information, and thus such an answer is only appropriate to certain questions, which have certain background information. These are different with (43) and

(47) What does Johan like?

Congruent answers to these questions will have to have different focus. Both of these questions can have

(48) Johan likes soccer.

as their answer, but this sentence has to have a different intonation to be a congruent answer in these cases. Here the focus will be intonational, and not structural as in the clefted sentences above.

What is background also affects what elliptical answers are appropriate. For example, to (43) one can simply answer

(49) Johan

and to answer (47) one can simply say

(50) soccer.

This phenomenon, often called background deletion, reflects that what is requested is just the new aspect of the information, and that the assumed background of the question, basically 'x likes soccer' and 'Johan likes $x^{\prime}$, can be dropped.

This relationship between questions and answers gives rise to a test of whether a particular utterance of a sentence comes with a focus, and background deletion allows us to determine what the focus is. We can simply see if the sentence would be an appropriate answer to a certain question, and what subsentential phrase would be an equally appropriate answer. The first part of this test will determine whether there is a focus; the second part will determine what the focus is. This test will be used below.

3.4 Another look at the loaded counterparts: the numbers case

We can now use these considerations to see quite easily that the loaded counterparts have a focus effect. To do this we should see how they interact with questions in ordinary communication, and how an utterance of an innocent statement differs from that of the corresponding loaded counterpart.

Consider the following situation:

I visit your town for the first time, don't know my way around well, and would like to get a quick lunch. You suggest a pizza place and a bagel shop that are close. Half an hour later you see me again and ask me

(51) What did you have for lunch?

I reply

(52) The number of bagels I had is two.

Obviously, this is odd. To be sure, what I said might be true and it gives you the information that I went to the bagel shop. But in putting it the way I put it, I did not bring out directly whether I had bagels or pizza. What I stress is how many bagels I had. Since this is not of importance here, and not what you asked me about, it makes my utterance somewhat off. If I had said

(53) I had two bagels.

then this wouldn't have been odd. Here how many bagels I had isn't focused on (assuming no special intonation). I told you that I had bagels, and furthermore that I had two of them. With (52) I tell you that I had two, and furthermore that it was bagels. 
Suppose I utter (53) instead of (52), you misunderstand me as having said that I had twelve bagels, and you ask me:

(54) Oh my God! You had twelve bagels?

To this I could reply

(55) No, I had TWO bagels.

or

(56) No, the number of bagels I had is two.

This is now perfectly appropriate. What matters now is how many bagels I had, not what I had. What I had for lunch has already been communicated correctly; what is still at issue is how many I had.

As simple as it is, this is the different use we have for (52) and (53) in ordinary communication. They have a different effect on a discourse and they interact differently with questions. And the reason for all this is now easy to see. (52) has a focus effect - it focuses on 'how many' - and that is why it is not an appropriate answer to the question what I had for lunch. (53), on the other hand, does not by itself come with this focus: it has to get it through intonation. This situation is quite analogous to the clefted sentences, where the focus effect was guaranteed by the syntactic structure of the sentence and the special positioning of the clefted item. Just as in the cleft construction, we use the loaded counterpart in communication for its focus effect. This will help us solve our syntactic and semantic semantic puzzles.

\section{Explaining the focus effect}

We have seen in the previous section that, in the case of numbers at least, the innocent statement and its loaded counterpart have quite a different effect on discourse. One of them brings with it a certain focus effect, independent of intonation; the other one doesn't. Now we have to ask ourselves: why is this so? What about these two statements can explain the difference in focus effect that they have? To ask this question is not to ask a metaphysical question but simply a question about natural language. And like any question that asks for an explanation of a certain phenomenon in natural language, this is not an easy question to answer in full detail. Nonetheless, it is often easy enough to see how such an answer will have to be given in outline, and this is also the case here. We will see that the common assumption of the standard accounts - that the loaded counterparts involve extra semantically singular terms - is incompatible with the occurrence of the focus effect we get without special intonation. In this section we will present the argument that this is so and propose a different account instead We will first focus on the case of numbers in this section, and then discuss the other two cases.

4.1 The argument against the standard solutions

According to the standard accounts, the loaded counterpart in the case of numbers is a statement asserting that what two semantically singular terms stand for is identical. That there is a tension between the standard accounts and the focus effect can be seen simply from the fact that there ordinarily is no focus effect in identity statements. According to all of the standard accounts, (5) is an identity statement, analogous to (10). In particular, 'the number of moons of Jupiter' is a singular term that attempts to stand for an object, and succeeds in standing for an object in literally true statements of the right kind, which include identity statements. But identity statements all by themselves do not give rise to a similar focus effect. An utterance of (10) does not bring with it a particular focus, unless, of course, through intonation. This restriction is crucial. With intonation we can achieve a focus effect even in identity statements, or in any other statement for that matter. And such a focus effect can be achieved through quite subtle changes in intonation. For example, a standard utterance of an identity statement will give a particular stress to one of the terms, and a slightly different stress to the other one, depending on the context of the utterance and what the topic of the conversation is. And such a stress can put a focus on one or the other of the terms, but it is intonational focus, not structural. This is important to keep in mind when the claim that identity 
statements don't have a structural focus is verified. I will elaborate on this claim in more detail in the next section, where I will also discuss some examples that might suggest otherwise. Suppose (at least until we get to the next section where it will be defended in greater detail) that identity statements do not have a structural focus effect. That is, suppose it is true that the syntactic structure of an identity statement does not guarantee that there is a focus effect in an utterance of this sentence. Then how can a believer in the standard solutions, which holds that (5) is an identity statement, explain that there is a focus effect in utterances of (5)?

One possible explanation compatible with the standard accounts is a pragmatic explanation. We saw above that there is a puzzle about the innocent statements and their loaded counterparts arising simply from the fact that they seem to give us systematically two ways to say the same thing. But if there were no difference at all between them, wouldn't one get a violation of a pragmatic principle (like one of Grice's maxims) if one were to utter a loaded counterpart rather than an innocent statement, since it is more complicated and involves more words? We now know that there is a relevant difference between them, namely a different focus effect. But maybe a believer in the standard accounts can turn this around and try to explain the focus effect as arising from pragmatic principles. This could, very roughly, go something like this:

When a hearer hears an utterance of a loaded counterpart he will recognize that the speaker also had the innocent statement available to communicate the same information. Thus the speaker is not communicating as efficiently as possible. From this the hearer reasons that the speaker is attempting, not only to communicate particular information, but also to focus in a particular aspect of the information.

Sketchy as this is, there are several problems with such an account. First, it isn't clear why the hearer should conclude from the violation of the pragmatic principles that the speaker is attempting a certain focus and not something else. And, second, it isn't clear how the hearer could determine what it is that is supposed to be focused on. Why should the hearer think that the focus is on how many moons Jupiter has, in our example, as opposed to the fact that Jupiter has that many MOONS, or that it is Jupiter that has four moons, or any of the other options. A purely pragmatic account has to bridge the gap between there being a violation of some pragmatic principle and the hearer's concluding that the speaker is attempting to place focus on a particular aspect of the information communicated. And this has to be done without locating the source of the focus effect somewhere else, say, in the syntactic form directly. I can't see how this could be done. And intuitively it is clear what settles this issue. It is the syntactic structure of the sentence that makes it clear to us that the focused item is a particular one.

To say that the focus effect does not arise from pragmatics is not to say that there are no pragmatic aspects to focus, at least not given a certain way to understand the difference between semantics and pragmatics. For example, in contrastive focus we implicitly take recourse to alternatives. When we stress that JOHAN likes soccer, we implicitly contrast him with a certain group of people. Which group of people that is will be determined by context, or pragmatically, given a particular understanding of this term. To be more precise, which group of people it is could be understood as a primary pragmatic process, in the sense of Recanati in [Recanati, 1993], and this can be incorporated into the truth conditions when it needs to be, for example if we add 'only' to the sentence. Such a view is in no way incompatible with the above argument. The argument was simply meant to show that a purely pragmatic story is not available to explain why we have a focus effect in the loaded counterparts, and what is focused on. An explanation like the one given next will have to be relied on instead.

4.2 The explanation

Focus, as we have seen, can arise from either the intonation of the sen- 
tence uttered or from the syntactic structure of the sentence uttered. The only reasonable explanation of the relationship between syntactic structure and focus, as well as intonation and focus, is that these are basic parts of the language, and that implicit knowledge of these relations is part of language competence. A competent speaker of a language will have knowledge not only of which sentences are well formed, what the words of the language mean, and how the meanings of the simple parts determine the meanings of the complex parts, but also of how the intonation of a sentence affects focus, among other things, and how the syntactic structure of a sentence affects focus. This does not dodge trying to give an explanation, but it is to assert that such an explanation can't be gotten from any other parts of the linguistic competence of speakers, such as purely pragmatic or purely semantic mechanisms. ${ }^{20}$ Intonational focus and structural focus are basic areas of competence that speakers of a language have to have. This does not mean that no uniform story can be told when such focus arises. It is, however, very hard to tell this story. What intonation or syntactic structure leads to what focus effect? We can't begin to get into this here, though I'd like to point to a number of related cases of structural focus that will be informative for our overall discussion.

Even though it is hard to give an account when exactly we get structural focus, there are some paradigmatic cases that are worth looking at. Structural focus is often associated with what is called "extraction". Extraction constructions are constructions in which a phrase appears in a position contrary to its canonical position. For example, in

(57) Quietly is how Mary entered.

or

(58) Quietly Mary entered.

the adverb 'quietly' appears outside of and away from the verb phrase it belongs to. Using the usual movement metaphor in syntactic theory,

20. See also [Rochemont and Culicover, 1990], 148f. we can say that it was moved or extracted to the front, away from the verb phrase. And such extraction brings with it a focus effect. That's why (57) has a focus effect without special intonation, but

(59) Mary entered quietly

doesn't. And exactly this seems to be the case with (2) and (5). In (5) the word 'four' is extracted from its canonical position next to the noun together with which it forms a quantified noun phrase, and put in a position contrary to its canonical position. That's why (5) has a focus effect without special intonation, but (2) doesn't. In fact, that the focus effect is in (5) rather than (2) can be seen as evidence that the canonical position of 'four' is to be part of a quantified noun phrase like 'four moons' rather than to stand all by itself. If its canonical position were the one it occupies in (5) or if neither were a canonical position, then the explanation of the focus effect would be more difficult, if not impossible. The claim in this paper does not rely on there being a canonical syntactic position for number words, but this stronger claim is defended in [Hofweber, 2005a].

It is also worth noting here that other extraction constructions are not available to bring out the determiner. For example, one can't use the cleft construction to extract the determiner, as in the ungrammatical

(6o) *It is four which Jupiter has moons.

To extract the determiner from (2), one can't take recourse to a cleft sentence, but one has to take recourse to (5) instead. ${ }^{21}$

This, in rough outline at least, explains why we get a focus effect without special intonation with (5), and why we don't have such a focus effect with (2).

The mere fact that there is structural focus is most instructive for

21. Of course, once one has (5) one can form a clefted sentence and extract from (5), as in

(61) It is four which is the number of moons of Jupiter. But this is derivative on (5) rather than on (2) directly. 
our general discussion. It shows that a simple view of the relationship between syntactic form and truth conditional semantics is mistaken. Syntactic form is not only related to the truth conditions of a sentence; it is also related to what focus an utterance of such a sentence will have. What part of a sentence has syntactically a special position should not directly lead one to conclude that this part has a special semantic or truth conditional function. In particular, what "singular terms" occur in a sentence is not directly linked to how many referring or denoting terms occur in that sentence. A particular part of a sentence can be extracted into singular-term position for a structural focus effect, but this does not have to affect the truth conditional interpretation of the sentence. I would like to note this more general fact here, but we won't directly rely on it in its generality below. We will merely discuss our three cases of numbers, properties and propositions here.

We have seen what explains the occurrence of the focus effect in the loaded counterparts in the case of numbers. We are now in a position to solve the semantic puzzles in the case of numbers, and then to extend this solution to the cases of properties and propositions. Before we do this, let me first give some more support to the claim that identity statements don't have a focus effect without special intonation.

\section{Focus and identity statements}

My argument against the standard accounts of the loaded counterparts relied on the claim that identity statements do not come with a structural focus effect. That is to say, the syntactic structure of the sentence uttered does not determine a focus effect in that utterance. But there are some examples of what appear to be identity statements that seem to be in conflict with this claim..$^{22}$ In this section we will first look at two kinds of examples where the order of the identity seems to make a crucial difference, and then at the question whether certain focus constructions, in particular pseudo-clefts, are identity statements.

22. Brit Brogaard suggests in [Brogaard, forthcoming] that some examples similar to the ones discussed in this section speak against the view I defend in this paper. I disagree for the reasons given below.

\subsection{Asymmetric identity statements}

Take a paradigmatic identity statement, like

(62) Cicero is Tully.

This sentence can be uttered as an answer to both of the following questions:

(63) Who is Tully?

(64) Who is Cicero?

However, as an answer to (63) it has to have a different intonation than as an answer to (64). (I have to ask readers to briefly verify this for themselves.) If we stick to one of these intonations in both cases then it becomes an incongruent answer to one of these questions. This is no surprise. Different questions require answers that present information with a different structure, even if it is the same information. For example, (63) asks about Tully, and thus makes Tully the topic of the conversation. The answer should say something about him, in particular who he is. What the topic of a sentence is, is usually marked phonetically. A particular intonation of the sentence brings out what the topic of that particular utterance of this sentence is. And in our case here we have the same sentence, but a different intonation either makes the first or the second term the topic of the sentence. Commonly the topic is in the subject position of a sentence, but this doesn't have to be so. It isn't, for example, when (62) is given as an answer to (63). A classic example in the linguistic literature that makes the same point is the following. ${ }^{23}$ Consider the sentence

(65) Fred ate the beans.

It can be a congruent answer to each of the following two series of questions:

(66) What about Fred? What did he eat?

23. See [Jackendorff, 1972], $258 \mathrm{ff}$. 


\section{(67) What about the beans? Who ate them?}

But to be a congruent answer the intonation has to be different in each case. The intonation has to mark the topic of the sentence properly, which is either John or the beans, and it has to focus on the other part, again, either John or the beans. The topic does not have to be what is in the subject position of the sentence uttered, as it isn't when (65), properly pronounced, is given as an answer to (67). In this case the beans are the topic, as is required by the question, and that John ate them is what is said about them, and so John is put into focus. This focus and topicalization are simply the result of the intonation of the sentence. We won't have to discuss here how intonation does that, and which intonation does what. This is the topic of an extensive debate in the linguistic literature, but all we need here is that this happens, not how precisely it happens. ${ }^{24}$

Examples like (62) suggest that what the topic and the focus are in an identity statement is simply a result of intonation. It seems that the term in pre-copula position as well as the one in post-copula position can be either one of these, with proper intonation. Thus the syntactic structure of the sentence does not determine a particular focus, and so there is no structural focus effect.

However, this symmetry does not always seem to hold. Some identity statements seem to be asymmetrical in that one of the terms has to be in subject position. These are examples that might suggest that there is a structural focus effect in an identity statement after all. These are the cases we will have to look at more closely. I will discuss two such cases in the following. For both of them, I will argue, the explanation for the asymmetry has nothing to do with a structural focus effect: why there is an asymmetry has a different explanation.

Our first case of an asymmetry concerns answers to questions like 'Who is $X$ ?' When we ask 'Who is $X$ ?' then identity statements formed with proper names can be used symmetrically, given proper intona-

24. For more on how topic is marked phonetically, see, for example, [Büring, 1997]. tion, to form a congruent answer. The examples (62), (63), and (64) illustrate this. The same seems to be true when we ask a question involving a description, and answers that involve a description and a name. Consider:

(68) Who is the composer of Tannhäuser?

(10) The composer of Tannhäuser is Wagner.

(69) Wagner is the composer of Tannhäuser.

Again, proper intonation is required for these answers to be congruent with the question, but the order of terms does not seem to be essential. But now consider the following. Suppose you ask

\section{(70) Who is Wagner?}

Then the order of terms seems to matter. It is perfectly fine to answer with (69), but it is awkward to answer with (10), even when one tries to straighten things out with intonation. Why is that?

I won't be able to give a full explanation of all the relevant data here, but what is of crucial importance is to see whether the explanation could be that an identity statement involving a description in subject position comes with a structural focus effect, one which somehow makes (10) an incongruent answer to the question (70). But this explanation we can rule out right away. Notice that sometimes identity statements involving descriptions in subject position are perfectly fine answers to questions like (70). Consider, for example

(71) The man to your left is Wagner.

or

(72) The conductor is Wagner.

These are perfectly congruent answers, given proper intonation. If identity statements involving such descriptions had a structural focus effect, it should apply to all such cases, but it clearly doesn't. The explanation why (10) is an incongruent answer to (70) thus has to be 
something else. Why are some descriptions OK while others are not? In outline, I think the explanation is along the following lines.

For an utterance to be a congruent answer to (70) it has to have Wagner as its topic, since Wagner is the topic of the question. Usually, in English at least, the topic is in subject position, but it does not have to be in that position. The topic can be in post-copula position, as in the examples above, provided that it is phonetically marked as the topic. But when the pre-copula material is long and complicated, as in (10), it is hard to get the reading where Wagner is the topic, since it is so late in the sentence, and thus we naturally take the pre-copula term to be the topic. When trying to understand the sentence we naturally try to give it a topic, and if the pre-copula material is complex, it is hard to make the post-copula name the topic. This explains why $(72)$ is OK but (10) is not. However, an exception to this seems to occur when the object denoted by the pre-copula material is salient to the speaker, as in (71). This somehow makes it easier to parse the sentence as having a post-copula topic. The details of how this happens don't have to be worked out in this paper. What matters to us here is that the explanation for these asymmetries in identity statements do not arise from identity statements' having a structural focus effect. I hope the examples given above make this clear.

There is also a second case of asymmetry in identity statements, which has a different explanation than the above cases. It can be seen when we consider answers to questions like

(73) What has Wagner ever done?

(10) is not a congruent answer to it, but (69) is. In this case the contrast is even stronger than in the above cases. How should we explain this asymmetry?

As a first step we should notice that here it is more puzzling that (69) is a congruent answer than it is that (10) isn't one. Why would an identity statement be a congruent answer to a question about what Wagner has done? After all, we are not asking who Wagner is, but what he did. An identity statement seems to tell us who he is, but not what he did. In fact, this is where the difference in the two answers lies. (10) is not a congruent answer because it is an identity statement and thus doesn't address the question. But (69) is a proper answer in part because it is in fact not an identity statement when used as an answer to the question. The description in (69) is in predicate position, and it functions as a predicate that specifies a property the subject is claimed to have. ${ }^{25}$ Thus, on a standard reading (69) does not say that Wagner is identical to the unique thing which composed Tannhäuser. Rather it says that Wagner has the property of being the composer of Tannhäuser. And this property is closely tied to the property of having composed Tannhäuser. Composing is an activity and thus something Wagner has done. This is why (69) addresses the question and is a congruent answer to it, but (10) is not.

The fact that the description occurs as a predicate in (69) then raises the question why it can be a congruent answer to (70). If the postcopula term does not denote an object with which Wagner is identical, then why does (69) answer the question? Questions like (70) have two kinds of congruent answers. ${ }^{26}$ The first is one in which the topic is identified with an object that is familiar to the person addressed. The second is one in which the speaker specifies a distinguishing property of the topic. Thus I can answer either with an identity statement or with a subject-predicate sentence that specifies some special properties of Wagner. The latter is the case when I use (69); the former is the case when I answer with (10).

None of this is in conflict with our claim that identity statements do not have a structural focus effect. That there is an asymmetry in such identity statements - i.e., that sometimes they are a congruent answer to a question when one term is in subject position and sometimes when the other one is - does not show that there is a structural focus effect in identity statements. We have seen above how, in out-

25. See [Partee, 1987] for more on predicative uses of descriptions. 26. See [Boër and Lycan, 1986]. 
line, these asymmetries are to be explained, and that a structural focus effect couldn't explain the data.

5.2 Pseudo-clefts as identity statements

A further objection holds that some uncontroversial focus constructions are identity statements, and thus that identity statements can have a structural focus effect after all. We will see that this objection should not bother us too much, either, since it uses a different sense of 'identity statement' than the one that is relevant for our discussion.

A paradigmatic case of a focus construction is a pseudo-cleft, like

(74) What John likes is pie.

This construction is similar to a standard cleft, or it-cleft, which we discussed above. It, too, clearly has a structural focus effect. It has been argued, however, that this sentence is an identity statement, and if this were right then identity statements might have a structural focus after all. In this section we will look at these arguments and whether this is so.

Pseudo-clefts are of interest in the linguistics literature in part because they seem to give rise to counterexamples to the principles of Binding Theory, an otherwise well supported theory. For example,

(75) What John likes is himself.

requires the reflexive pronoun 'himself' to mean that John likes John. But Principle A of Binding Theory says that this should only be so if 'John' c-commands 'himself', which is true in

(76) John likes himself.

but appears to be false in (75). ${ }^{27}$ One attempt to save the principles of Binding Theory is to treat pseudo-clefts as questions in disguise. According to this approach the syntax of $(75)$ is something like this:

27. For more on this problem, called the connectivity problem, its significance, and an overview of attempts to solve it, see [Schlenker, 2003].

\section{(77) [What John likes - ] is [fohn likes himself]}

Here the pre-copula position is occupied by a question, and the postcopula position by an answer to it. The struck-out material is simply omitted, either phonetically or at some other level. A proposal of this kind is made, for example, by Phillipe Schlenker in [Schlenker, 2003]. It would save Binding Theory, since 'himself' now is c-commanded by the second 'John'. What is crucial for our purposes here is that Schlenker in addition claims that this analysis makes (75) into an identity statement. But since (75) clearly has a structural focus effect this seems to be in conflict with our claim that identity statements don't have a structural focus effect. This aspect of Schlenker's proposal thus needs to be discussed.

Schlenker holds that pseudo-clefts are identity statements on the concealed-questions analysis, given that one has a certain view of the semantics of questions. Suppose that one adopts Groenendijk and Stokhof's semantics for questions [Groenendijk and Stokhof, 1997], on which the semantic value of a question is a proposition, namely the proposition which is the unique exhaustive answer to the question. Then we can understand (75) as an identity statement in the following sense. (75) is true iff the semantic value of the pre-copula position, i.e. the proposition which is the semantic value of the concealed question, is identical to the semantic value of the post-copula position, i.e., the proposition which is the semantic value of the elided answer. In this sense Schlenker holds that $(75)$ is an identity statement. However, this is a different sense of being an identity statement than the one under discussion in the present paper. For our purposes here an identity statement is a statement that says that what two singular terms refer to or denote is one and the same thing. Identity statements in this sense are thus statements that have semantically singular terms in pre- and post-copula position. In Schlenker's sense a statement is an identity statement iff it is true just in case the semantic value in the pre- and post-copula position is one and the same. These are different senses of being an identity statement. For one thing, an identity statement in 
our sense does not have to be one in Schlenker's sense. For example, (10), which is an identity statement in our sense, formed with a definite description and a proper name, won't be an identity statement in Schlenker's sense since the semantic value of a description will be different from that of a name, even if they denote the same object. And an identity statement in Schlenker's sense does not have to be one in our sense. Phrases that are not semantically singular terms don't have referents, but they still have semantic values. Almost any phrase has a semantic value, but they do not refer to their semantic values. 'Very' has a semantic value, but it is not a referring expression. ${ }^{28}$ Questions are another example of this. Such phrases can form identity statements in Schlenker's sense but not in ours. And pseudo-clefts as concealed questions is just such a case. The question and the answer are not singular terms: they do not aim to pick out objects. But their semantic values can be the same. Thus in Schlenker's sense a pseudo-cleft can be an identity statement, but this is not the sense in which I deny that identity statements have a structural focus effect. Schlenker's understanding of pseudo-clefts is, subtleties aside, compatible with the view taken in the present paper.

I conclude this section by restating that identity statements do not have a structural focus effect. By an identity statement I mean a statement that says that what two semantically singular term stand for is one and the same entity. The asymmetries that identity statements can exhibit in communication are not to be explained with a structural focus effect but relate to issues of topicalization, predicative uses of descriptions, and other phenomena.

\section{A solution to the syntactic and semantic puzzles}

To solve the semantic puzzles about the relationship between the innocent statements and their loaded counterparts, one has to do the

28. Since the word 'reference' is a bit of a philosopher's term of art, this can of course be denied, and others can choose to use it in such a way that all expressions refer to their semantic values. This would be using 'reference' in a different sense than the one that is under discussion here. following things, as listed at the end of section 1.2: one has to give an account of the obviousness of their equivalence, one has to solve the puzzle of extravagance, and one has to account for the particular syntactic and semantic features of the loaded counterparts. The last of these three tasks is different for the different cases, but the first two will be the same for each of the cases. We will start with numbers, which we focused on above, and then discuss the other two cases.

\subsection{Numbers}

The task of explaining our judgments of equivalence is met as follows. The loaded counterpart involves structural focus, which is closely connected to an extraction or movement that occurs in it. As competent speakers of our language, we are competent with the structural focus that our sentences give rise to - that is, we are competent with what syntactic structures give rise to what focus effect. As always with linguistic competence, this competence does not manifest itself in explicit knowledge of what structures do what, but rather in judgments of what utterance of what sentence is grammatical, appropriate, equivalent to another, and so on. We have seen such judgments about the loaded counterparts at work above in the bagel example. Thus, just like our judgments of the equivalence of a simple subject-predicate sentence and its cleft counterpart, our judgments of the equivalence of the innocent statements and their loaded counterparts are explained by our linguistic competence.

The puzzle of extravagance is also easily answered. The loaded counterparts do play a different role in communication. They give rise to a focus effect, which is an important aspect of communication. Thus, the loaded counterparts are no case of extravagance. They have a function in communication, and we can see why it is good for our language to have the loaded counterparts in addition to the innocent statements.

This leaves us with the syntactic and semantic puzzles about number words. We will restrict this discussion to the occurrence of number words in our examples. A more detailed discussion of these and other 
occurrences of number words in natural language can be found in my [Hofweber, 2005a], but these extra details are not important for our purposes here.

The case of numbers is different from the cases of properties and propositions in that the word 'four' already occurs in the innocent statement, though in an apparently different position. In such occurrences number words are like adjectives, as Frege already noted, or determiners, like 'some' or 'many'. ${ }^{29}$ In particular, 'four moons' can be a quantifier, like 'some moons', as in

(78) a. Four moons are covered with ice.

b. Some moons are covered with ice.

Unfortunately, these uses of number words have not being given sufficient attention in the philosophy of mathematics literature. This is partly because 'four moons' is first-order definable. ${ }^{30}$ 'Four moons' can be defined as there being some moon, and another moon, and another moon, etc. ${ }^{31}$ That 'four moons' is first-order definable does show something about 'four moons'. It does, for example, dispel any doubts about whether the quantifier has a determinate meaning, or at least it reduces these doubts to the case of first-order logic itself. This distinguishes 'four moons' from 'finitely many moons', which is not first-order definable, and of which some philosophers have claimed that there is a real issue whether it has a determinate content. ${ }^{32}$ But

29. There is a bit of disagreement in the literature about whether number words are adjectives or determiners. I take them to be determiners here and also in [Hofweber, 2005a], but this is not essential for the argument. The main conclusions are unaffected if it turns out they are adjectives. What matters for us here is that they are in the "adjectival" use not by themselves denoting expressions, or full singular terms.

30. See, for example, [Field, 1989a] or [Hodes, 1984], who make use of the first order definability of numerical quantifiers.

31. This defines 'four moons' in the reading 'there are at least four moons'. The reading 'there are precisely four moons' is, of course, also first-order definable.

32. See [Field, 2001]. of course, the first-order definability of number quantifiers does not give us a semantic analysis of number quantifiers. It doesn't tell us anything about what role 'four' plays in such uses. However, such an analysis is available. Within generalized quantifier theory (GQT) ${ }^{33}$ it is possible to give a uniform analysis of the semantics of determiners, expressions that together with a common noun form a quantified noun phrase, like 'some', 'the', 'all', 'many', 'three', etc. All of these determiners get the same kind of semantic value, and there is a uniform story about how they combine with a noun to form a quantified noun phrase. In particular, 'four' when it is used as a determiner is not a referring expression, just as 'some' is not a referring expression when it is used as a determiner. This, of course, does not preclude it from having a semantic value in the relevant semantic theory, just as 'some' has a semantic value in such semantic theories.

That 'four' in the determiner or adjectival use is not a denoting expression is in conflict with (A1), the first answer given to the problem how there can be something from nothing (see section 1.2). And this brings out a problem that any account of their relationship faces. How could it be that 'four' is not semantically a denoting expression in some occurrences but is in others? This is a problem that has to be answered no matter which general solution one prefers. The present account of the relationship between the innocent statement and its counterpart allows us to give an answer to this which was left out above. The answer is simply that 'four' is not a denoting expression in either the innocent statement or in the loaded counterpart. That structural focus arises from extraction and movement shows that it is the same word 'four', with the same semantic function, in both

(2) Jupiter has four moons.

and

(5) The number of moons of Jupiter is four.

33. See, for example, [Gamut, 1991] for the details. 
In (5), however, it is moved from its canonical syntactic position into an unusual position for the purpose of achieving structural focus. And this solves the puzzle. We don't get something from nothing. (2) and (5) have the same referring or denotational terms. There is no new referring term coming out of nowhere in (5). 'Four' is merely moved into a special syntactic position in order to achieve structural focus. ${ }^{34}$

\subsection{Properties}

The case of properties is different from the case of numbers. In the numbers case the word which is the new singular term, 'four', was already present in the innocent statement, although at a different syntactic position. In the properties case this is not so. The expression 'the property of being a dog' isn't already present in the innocent statement, but its foundation is. We can see the loaded counterpart arising from the innocent statement via nominalization of the whole verb phrase 'is a dog' into 'being a dog', which then gets embedded into 'the property of being a dog'. This suggest an analogy with the numbers case, in that the information that is carried by a particular aspect of the innocent statement, in this case the verb phrase, is moved into a singular-term position. And all this might happen to achieve a structural focus effect by moving the relevant material into a syntactically distinguished position. But to see whether this is indeed so, we have to see whether there is a focus effect in the loaded counterparts in the case of properties, if it is a structural focus effect, and what the focus is. If there is, and the focus is on the information contributed by the verb

34. It is worth pointing out that this account of the loaded counterparts in the case of numbers does not directly give an account of the function of number terms in statements that are of central relevance in the philosophy of mathematics to those who give Hume's Principle a central role. Since Hume's Principle:

(79) The number of Fs is the number of Gs iff there are just as many Fs as there are Gs.

introduces two number terms it is a different case than the one we have focused on here. Of course, an analogous treatment suggests itself, but it would be irresponsible to assert it without a more thorough discussion, which we have to reserve for another occasion. phrase, then our story will carry over from the case of numbers to the case of properties.

We know that there is a good test to determine if there is a structural focus effect in a certain sentence: we have to see to what questions a common utterance of the loaded counterpart would make a congruent answer. However, there is a difficulty here in that if we want to test for structural focus we have to make sure that the focus effect does not arise from intonation. And this is difficult to control since certain answers to certain questions invite a certain intonation. Often an utterance of a sentence will have a focus because a natural way to intonate that sentence at this point in the discourse will give rise to that focus. We have to make sure to distinguish structural from intonational focus in the following, but it isn't easy to do this. But by carefully considering the examples given below we can see that there is a structural focus effect in the loaded counterparts. To make this clear, lets look at some question-answer exchanges. Here we will also use background deletion as a test for what is in focus.

Consider a first example. To the question

(8o) I know gold is very valuable, but it's soft. I need something very hard. Which one of these metals is very hard?

any of the following answers are appropriate:

(81) a. Titanium.

b. TITANIUM is very hard.

c. It's titanium that's very hard.

Clearly the focus is on titanium, and that is exactly as we would expect it. The contrast class is the class of these other metals that are salient in the context of the question. Now compare this with the second exchange:

(82) I know gold is very valuable. Titanium is supposed to be special, too. But what's special about it? 
(83) a. Being very hard.

b. Being very hard is what's special about titanium.

c. Titanium is VERY HARD.

d. Titanium has the property of being very hard.

Here the focus is on being very hard. All of these answers focus on this, rather than titanium. That this is so can be seen by carefully considering these discourses, and by assuring oneself that a focus effect arises, and that it arises not from intonation, except, of course, in (83c). The examples above and their interaction with questions show that this is the case for the loaded counterpart in the case of properties.

Given that there is a structural focus in the loaded counterparts about properties, we can see quite easily that the solutions to the puzzle of extravagance and the problem of the obviousness of the equivalences carry over to this case as well. The loaded counterparts have a function in communication, and the equivalence is obvious from our linguistic competence. In the loaded counterparts involving properties, we move the information that was carried in the verb phrase and put it in a special nominalized position. This is done to achieve the above focus effect.

\subsection{Propositions}

In the case of both numbers and properties the loaded counterparts give rise to a structural focus, and what is focused on is only a part of the information communicated. In the case of properties, the focus is the information carried by the verb phrase in the corresponding innocent statement; in the case of numbers it is the information carried by the number determiner. We could say that what is in focus is information carried by a phrase below the sentential level - that is, it is subsentential focus. But in the case of propositions this is not so. There we do not have a structural focus effect in which only a part of the information communicated by the innocent statement is in focus, while the rest is moved into the background. Instead, all of the information is put into focus. All the information carried by the innocent statement is focused on, and thus what is in focus is at the sentential level: it is sentential focus. This makes the propositions case unique and interestingly different form the other two cases. That we get a focus effect in this case can again be seen by considering some sample exchanges of questions and answers. I will list two questions and a range of answers, all of which seem to be congruent to each of the questions.

(84) a. I have heard that Fido is a dog. Is he?

b. Is Fido really a dog?

(85) a. Yes.

b. Yes he is.

c. Fido IS a dog.

d. FIDO IS A DOG.

e. That Fido is a dog is true.

f. It's true that Fido is a dog.

Reflection on the question-answer exchanges above shows that our main concern here, (85e), has the same overall effect on the discourse as $(85 \mathrm{~d})$. It has the effect of simply emphasizing the content of the innocent statement. That is, it emphasizes the whole content, not just a part of it at the expense of some other part. This is what we called sentential focus. The emphasis does not affect the information communicated; it just emphasizes it. Emphasis on all of the information does not turn it into different information. $(85 \mathrm{~d})$ gives us sentential focus through intonation. ( $85 \mathrm{e}$ ) gives us the same focus effect without special intonation.

There are some subtle differences between $\left(8_{5} \mathrm{c}\right)$ and $(85 \mathrm{~d})$, and similar ones between $(85 \mathrm{e})$ and $(85 \mathrm{f})$. (85c), depending on subtleties of how the capitals are intonated, can either have a contrastive stress on the auxiliary verb or result in sentential focus. In the former case 
the contrast class might be something like \{Fido seems to be a dog, Fido looks like a dog, ... $\}$. These two are different, and it is hard to say which precise intonation gives rise to which one of them. Fortunately, we don't have to say. It is interesting to note that a similar and somewhat neglected difference also arises between

(85e)That Fido is a dog is true.

(85f) It's true that Fido is a dog.

(85e), without special intonation, gives rise to a sentential focus of the information carried by the that-clause. $(85 \mathrm{f})$, on a standard occasion of utterance, gives rise to a contrastive focus on 'true', with the contrast class, as always, depending on the situation of utterance, but likely to contain members like It's false that Fido is a dog, It's unlikely that Fido is a $\operatorname{dog}, \ldots\}$. Although $(85 \mathrm{f})$ is not quite a clefted sentence, it is very similar to one, and it does have a similar contrastive focus. Contrastive focus on 'true' and sentential focus on all the information carried in the clause are similar, but not quite the same.

The loaded counterparts in the case of properties and numbers result in subsentential focus on the part of the information carried by the verb phrase and the determiner, respectively. The loaded counterpart in the propositions case results in sentential focus on all the information carried by the innocent statement. This is one crucial difference, but there is also another one, which deserves further discussion, although a more thorough discussion will have to be postponed for another occasion. In the cases of properties and numbers, the words 'property' and 'number' play little to no essential role. To be sure, they have to occur to maintain grammaticality of the loaded counterparts, but they do not seem to contribute anything essential to the content that isn't already implicit in the other parts. But in the propositions case this is not so for 'true'. It does play a central role, and it does contribute something that isn't already implicit in the rest of the loaded counterpart. After all, the rest of the sentence can be the same, but we can replace 'true' with 'unlikely' to a rather different overall effect.
'True' thus plays a central role in giving rise to this focus effect. In fact, it might seem that this sentential focus is almost surprising, since after all, what was the innocent statement is moved into a clause and apparently put into the background. But combining it with 'true' gives us a sentential focus of just the information that was moved into the clause. In simple ascriptions of truth, as in the loaded counterparts, this is exactly what we use them for in ordinary communication.

To say that the loaded counterpart in the case of propositions gives rise to a sentential focus effect, and that the word 'true' plays a central role in it, is not to adopt a particular philosophical theory of truth more generally. We are concerned with the loaded counterparts as they occur in the trivial inferences. It is compatible with this that there is also a different use of 'true', for example, one that has some heavyduty metaphysical implications. To note that we get a focus effect in the loaded counterpart is compatible with this. It is compatible with this in the case of propositions just as it is compatible with the story defended here in the case of numbers that on other uses 'the number of Fs' is a definite description. That we get the general effect of emphasis in the case of ascriptions of truth has been noted in the philosophical literature about truth, for example [Strawson, 1964]. Here we have seen how this effect of emphasis fits into a larger picture of this aspect of communication.

\subsection{Quantification}

Before we move on to the solution of the metaphysical puzzle, we have to address one more largely linguistic issue. This issue is really beyond the scope of this paper, but it is important enough so that is should be discussed, even if only in outline. To do this I will briefly present the problem that needs to be addressed, and then outline the solution that I have developed elsewhere.

It appears that the solution to the syntactic and semantic puzzles spelled out above is incompatible with the inferential relationship that the loaded counterparts have with quantified statements. For example, if it is true that $(5)$ does not contain any new referring or denoting ex- 
pressions, and thus 'four' in it is not a semantically singular term, then how can we explain that (5) implies

(8) There is a number which is the number of moons of Jupiter, namely four.

It appears that for this inference to be valid it is required that 'four' denote an object which is in the domain of the quantifier in (8). But this seems to be in conflict with the present proposal. According to the present proposal, 'four' as it occurs in (5) is not a referring expression. So, how is the present proposal compatible with the fact that (5) implies (8)?

In fact, such an interaction with quantifiers is what Quine considered the mark of singular terms that are referential and that can't be understood in any other way than as aiming to refer to or denote objects. In [Quine, 1960, $233 \mathrm{ff}$.] he discusses a number of different cases to see whether the relevant terms have to interact with quantifiers. Those that don't, like 'sake', don't have to be understood referentially, whereas those that do have to be. Now, I have argued that the relevant singular terms in the loaded counterparts are not referential, and thus the question for us here is not really "Do we have to treat them as referential?" Issues of ontological economy played no role in our discussion here, and they shouldn't, contrary to Quine's discussion. But the question remains, How is this interaction of the singular terms with the quantifiers compatible with the non-referential account of their function?

To answer this question we will have to look at quantification in natural language in a little more detail, in particular how quantifiers relate to singular terms. To do this is somewhat involved, but in outline we can see how the relevant aspect of natural language quantifiers is to be understood, and how this relates to the present problem. For more of the details and the arguments, I will have to refer the reader to [Hofweber, 2000], [Hofweber, 2005b], and [Hofweber, 2006], where this view is spelled out in more detail.

Quantifiers clearly have at least the following use in ordinary com- munication. They are used to make a claim about the domain of discourse, that is, whatever the entities may be that are "out there" as part of reality, waiting to be talked about. This is the familiar reading of quantifiers, one that is paradigmatically used in ordinary utterances of sentences like

(86) Something fell on my head.

Many philosophers hold that this is the only function that quantifiers have in natural language: all they do is impose conditions on the domain of discourse. Since quantifiers clearly have this reading, which I will call the domain-conditions reading, or also the external reading, the question for us will be whether this is the only reading they have.

In natural language many phrases are polysemous: they have a variety of related readings, or meanings, in different uses. This is a very familiar phenomenon. Consider, for example,

(87) Before he got home he got some beer to get drunk.

The word 'get' means three different things in this sentence, although these meanings are related in certain ways. It is a polysemous verb, and so is basically every other verb and many other expressions. But a number of philosophers maintain that quantifiers are exempt from this. Quantifiers only have one reading, the external one-end of story, they maintain. It isn't too hard to offer an explanation how this persistent belief comes about. But it relies on belief in a myth.

There is a very powerful and still widely accepted picture of how a language is built that supports the view that quantifiers have only one function. I think this picture is mistaken, and I'll call it the myth of the logical skeleton. This myth goes as follows. Language is divided into two parts. One is the soft part. It is full of ambiguity, polysemy, and vagueness. It includes words like 'get', which in English can mean almost anything. And it is most of language. The other part is the hard part, which is the skeleton which holds up the softer parts. This skeleton consists of logic: Boolean connectives and quantifiers. They are different from the soft parts in that they are not polysemous and they 
do not have more than one function in communication. But this is a myth. There is no such division within language. What seems like the hard part is just as soft as the rest. This is widely acknowledged for expressions like 'and', 'or', negation, and conditionals like 'if ... then'. There are many uses of these expressions that are not Boolean sentential operations. For example 'and' in natural language combines not only sentences but noun phrases, verb phrases, and other categories, and such combinations can have different readings - for example, collective and distributive readings. And things are even worse with negation and conditionals. I hold that quantifiers as well have more than one reading. They are not always used to range over a domain of objects, but nonetheless it is one and the same quantifier phrase that has these different readings. Quantifiers are polysemous.

Beside the domain-conditions reading, quantifiers also have an inferential role reading, or also internal reading. ${ }^{35}$ In this reading sentences with quantifiers are inferentially related to sentences without such quantifiers (in the simplest case). For example, the quantifier 'something' in this reading has the inferential role that 'Something is $\mathrm{F}^{\prime}$ follows from each instance ' $\mathrm{F}(\mathrm{t})$ ', for any term ' $\mathrm{t}$ ' in the language. I have argued in [Hofweber, 200o] that we do have a need in ordinary communication to have an expression that plays exactly this role. This need has nothing to do with metaphysics but rather with a need to communicate information in a situation of partial ignorance. But in a language like ours, where not every term denotes an object in the domain of discourse, and not every object is denoted by a term, no single contribution to the truth conditions can yield both a domain condition and an inferential role. In the limit, when every term denotes an object and every object is denoted by a term, these two can coincide, but in our language they do not.

Suppose now that this view of quantification is correct. Then the

35. The terms 'internal' and 'external' are used for these readings in part because they make a connection to Carnap's distinction between internal and external questions. However, on the present approach both internal and external readings of quantifiers are fully meaningful. For more on this connection to Carnap, see [Hofweber, 2005b]. This terminology will also be used below. view of the loaded counterparts defended in this paper is compatible with the quantifier inferences discussed above. Furthermore, it explains why they seem to be so trivial. If a quantifier is used in its inferential role reading then it is completely trivial to use it in inferences that correspond exactly to its inferential role. For example, if we use 'something' in its inferential role reading then the inference from 'Being a philosopher is fun' to 'Something is fun' is trivial, since this corresponds exactly to its inferential role. It does not matter for this what the semantic function of the relevant singular term 'Being a philosopher' is in this inference. And the same is true for the quantifier 'a number' in (8). In its inferential-role reading the above inference is trivial, no matter what the function of 'four' is in (5). Thus in their inferential role reading quantifiers can inferentially interact with singular terms even if they are terms in the service of focus, not reference. In fact, if the quantifier is not used in its inferential-role reading in inferences like the one from (5) to (8), then the inference would not at all be trivial. If it is used in its domain-conditions reading then the inference is valid only if the relevant singular term aims to refer to an object. But this is not trivial, and in our case not even true. In the sense in which (8) is a trivial consequence of (5), the quantifier in (8) is used in its inferential-role reading. But as such the validity of this inference is compatible with the view about the loaded counterparts defended in this paper. ${ }^{36}$

\section{A solution to the metaphysical puzzle}

\subsection{The solution}

The standard solutions to the metaphysical puzzle took the new singular terms in the loaded counterparts as aiming to refer to new and different entities. This is a paradigmatic function of singular terms, and to think that these singular terms aim to do just that is thus understandable. However, we have seen that in these cases the singu-

36. More details of this view of quantification, again, are spelled out in [Hofweber 200o], and more on trivial quantifier inferences and what not to conclude from them are spelled out in [Hofweber, 2005b] 
lar terms have a quite different function. They do not aim to refer to some new entities; rather, they are in the service of putting syntactic material into certain distinguished positions to achieve a focus effect. We have seen, using cases other than the loaded counterparts, that there is this correlation between syntactic position and focus effect, and that the general connection between having the syntactic position of a singular term and having the semantic function of referring can thus come apart. The loaded counterparts have a focus effect, and this focus effect is a structural focus effect, with the help of 'true' in the propositions case. The new singular terms are thus in the service of focus, not reference.

All this suggest another solution to our metaphysical puzzle how we can get something from nothing:

A5 We don't get something from nothing, even though the Frege biconditionals are true. The loaded counterparts do not contain more referring expressions; they are focus constructions.

This solution is supported not primarily by metaphysical considerations, like ontological parsimony. It is rather supported by syntactic and semantic considerations about the loaded counterparts and their role in communication.

\subsection{The bigger picture}

In this paper we focused on the syntactic and semantic aspects of the relationship between the innocent statements and their metaphysically loaded counterparts. The view presented gives us a new solution to the metaphysical puzzle, but it does not give us a view in the metaphysics of numbers, properties, and propositions. Questions about the existence of such entities are completely left open by what has been shown in this paper. But there are a number of connections to larger issues in the metaphysics of numbers, properties, and propositions. Here I will briefly outline some of them and refer to other work where these are developed further.
Even if the number words, property nominalizations, and that clauses are not referential expressions in standard uses of the loaded counterparts, the real question for the larger metaphysical debate will be whether they are referring expressions in other uses, and if so, which ones, and why. To settle this question we have to go beyond the puzzle how talk about numbers, properties, and propositions can be introduced from nothing, to the question what we do when we talk about them in general. The discussion so far gives us the tools to formulate two large scale views about this. These two views can be formulated for each of numbers, properties, and propositions separately, and whether one or the other is true is a separate question in each case. Let's use numbers again as our example. The other two cases are analogous. First, there is externalism about (talk about) numbers. It holds that talk about numbers aims to describe a domain of entities, the numbers. Thus, generally number words are denoting expressions, and generally quantification over numbers is external quantification, i.e., quantifiers used in their domain-conditions reading. Anyone who accepts externalism about numbers will hold a certain semantic view about number words in general, although it might not be incompatible with this view to hold that number words in (standard uses of) the loaded counterparts are as this paper claims they are. Second, there is internalism about (talk about) numbers. An internalist holds that number words generally are not denoting expressions, and that generally quantification over numbers is internal quantifications, i.e., these quantifiers are used in their internal reading. An internalist will find the present paper congenial, but it is nowhere near a defense of internalism by itself. The question for an internalist will be, What function do number words have outside of the loaded counterparts, given that they are not referring expressions? And similarly for properties and propositions.

I believe internalism is true about numbers, properties, and propositions. But to be clear, I don't claim to have argued for it in this paper. This paper simply defends an internalist line for one particular case of talk about numbers, properties, and propositions, a case that is es- 
pecially puzzling. In fact, the standard solutions to the puzzle how we can get something from nothing are in the grip of an externalist picture of the function of talk about numbers, properties, and propositions in literal discourse. Ultimately, this picture has to be rejected, but the account of the loaded counterparts from this paper does not require a rejection of this larger picture. I have defended other aspects of an internalist picture of talk about numbers in [Hofweber, 2005a] and of talk about properties and propositions in [Hofweber, 2006]. In this paper I have argued that certain puzzling occurrences of number words, that-clauses, and property nominalizations are not denoting expressions. In the papers cited I have argued that in general they are not denoting expressions, but this is a substantial further claim.

\subsection{Content carving without tears}

Frege said that we can carve up content in different ways. ${ }^{37}$ But Frege left us with a mystery how this is supposed to be understood. In particular, how is it possible that the same content can be carved up one way and be about certain objects, but also carved up another and be about different objects. This suggestive metaphor for the relationship between the innocent statements and their metaphysically loaded counterparts can now be spelled out, and this mystery can now be solved. We can indeed carve up content in different ways. Different aspects of the same content can be brought out, emphasized and stressed. The syntactic form of the sentences used to communicate that content matters for what is emphasized and brought out. In this way we do carve up content differently. We can give the same information a different structure, and the sentences we use to communicate this structured information reflect this. But we do not communicate the same content by talking about different objects; we communicate the same content by focusing on different aspect of what we say. There is no mystery about it, and we can see how one can be lead to consider content carving to bring out different objects, since the sentences that

37. See [Frege, 1884], §64. express the newly carved content contain new and further singular terms. But these singular terms are in the service of focus and information structure, not reference. Carving content is a great idea, and we do it all the time. However, it isn't a deep metaphysical mystery, but something rather mundane. It is the result of raising one's voice, or the syntactic equivalent of it. ${ }^{38}$ 


\section{THOMAS HOFWEBER}

\section{References}

[Alston, 1958]

Alston, W. Ontological commitment. Philosophical Studies 9:8-17.

[Boër and Lycan, 1986]

Boër, S.E., and Lycan, W. G. Knowing who. Cambridge, Massachusetts: MIT Press.

[Brogaard, forthcoming]

Brogaard, B. Number words and ontological commitment. Philosophical Quarterly.

[Büring, 1997]

Büring, D. The Meaning of Topic and Focus - the 59th street bridge accent. London: Routledge.

[Dummett, 1973]

Dummett, M. Frege: philosophy of language. London: Duckworth.

[Field, 1989a]

Field, H. Platonism for cheap? Crispin Wright on Frege's context principle. In [Field, 1989b].

[Field, 1989b]

Field, H. Realism, Mathematics, and Modality. Oxford: Blackwell.

[Field, 2001]

Field, H. Which undecidable mathematical sentences have determinate truth values? In Truth and the Absence of Fact. Oxford University Press.

[Frege, 1884]

Frege, G. Die Grundlagen der Arithmetik: eine logisch mathematische Untersuchung über den Begriff der Zahl. W. Koebner.
Innocent Statements $\mathcal{E}$ their Metaphysically Loaded Counterparts

[Gamut, 1991]

Gamut, L. Logic, Language, and Meaning, volume II. Chicago: University of Chicago Press.

[Groenendijk and Stokhof, 1997]

Groenendijk, J., and Stokhof, M. Questions. In van Benthem, J., and ter Meulen, A., editors, Handbook of Logic and Language, pp. 1055-1124. Cambridge, Massachusetts: MIT Press.

[Hale, 1987]

Hale, B. Abstract Objects. Blackwell.

[Hale and Wright, 2001]

Hale, B., and Wright, C. The Reason's Proper Study. Oxford University Press.

[Hardie, 1968]

Hardie, W. F. R. Aristotle's Ethical Theory. Oxford: Clarendon Press.

[Herburger, 200o]

Herburger, E. Focus and Quantification. Cambridge, Massachusetts: MIT Press.

[Hodes, 1984]

Hodes, H. Logicism and the ontological commitments of arithmetic. Journal of Philosophy, 81:123-49.

[Hofweber, 200o]

Hofweber, T. Quantification and non-existent objects. In Everett, A., and Hofweber, T., editors, Empty Names, Fiction, and the Puzzles of Non-Existence. CSLI Publications.

[Hofweber, 2005a]

Hofweber, T. Number determiners, numbers, and arithmetic. The Philosophical Review 114(2):179-225. 


\section{THOMAS HOFWEBER}

[Hofweber, 2005b]

Hofweber, T. A puzzle about ontology. Nô̂s 39:256-283.

[Hofweber, 2006]

Hofweber, T. Inexpressible properties and propositions. In Zimmerman, D., editor, Oxford Studies in Metaphysics, volume 2, pp. 155-206. Oxford University Press.

[Hofweber, 2007a]

Hofweber, T. From Remnants to Things, and back again. In Gary Ostertag, editor, Meanings and Other Things: essays in honor of Stephen Schiffer. Cambridge, Massachusetts: MIT Press.

[Hofweber, forthcoming]

Hofweber, T. Schiffer's new theory of propositions. Philosophy and Phenomenological Research.

[Jackendorff, 1972]

Jackendorff, R. Semantic interpretation in generative grammar. Cambridge, Massachusetts: MIT Press.

[King, 2002]

King, J. Designating propositions. The Philosophical Review 111(3): $341-71$.

[Krifka, 2004]

Krifka, M. The semantics of questions and the focusation of answers. In Lee, C., Gordon, M., and Büring, D., editors, Topic and Focus: a crosslinguistic perspective, pp. 139-151. Dordrecht: Kluwer Academic Publishers.

[Moltmann, 2003]

Moltmann, F. Propositional attitudes without propositions. Synthese 35(1):77-118.
Innocent Statements $\mathcal{E}$ their Metaphysically Loaded Counterparts

[Partee, 1987]

Partee, B. Noun phrase interpretation and type-shifting principles. In Groenendjik, J., de Jongh, D., and Stokhof, M., editors, Studies in Discourse Representation Theory and the Theory of Generalized Quantifiers. Foris Publications.

[Quine, 1960]

Quine, W.V.O. Word and Object. Cambridge, Massachusetts: MIT Press.

[Recanati, 1993]

Recanati, F. Direct Reference: from language to thought. Blackwell.

[Rochemont and Culicover, 1990]

Rochemont, M.S., and Culicover, P.W. English Focus Constructions and the Theory of Grammar. Cambridge University Press.

[Rooth, 1985]

Rooth, M. Association with Focus. PhD thesis, University of Massachusetts at Amherst.

[Rosen, 1993]

Rosen, G. The refutation of nominalism (?). Philosophical Topics, 21:149-186.

[Schiffer, 1994]

Schiffer, S. A paradox of meaning. Nous 28:279-324.

[Schiffer, 1996]

Schiffer, S. Language created, language independent entities. Philosophical Topics 24:149-167

[Schiffer, 2003]

Schiffer, S. The Things We Mean. Oxford University Press. 
[Schlenker, 2003]

Schlenker, P. Clausal equations (a note on the connectivity problem). Natural language and linguistic theory 21:157-214.

[Strawson, 1964]

Strawson, P. A problem about truth - a reply to Mr. Warnock. In Pitcher, G., editor, Truth. Prentice-Hall.

[von Stechow, 1991]

von Stechow, A. (1991). Focusing and backgrounding operators. In Abraham, W., editor, Discourse Particles, pages 37-84. John Benjamins.

[Yablo, 2006]

Yablo, S. The myth of the seven. In Kalderon, M., editor, Fictionalist Approaches to Metaphysics. Oxford University Press. 